1st International Conference - Global Ethics - Key of Sustainability (GEKoS) | May 15th, 2020 | Bucharest, Romania

\title{
Ethics and Open Sources
}

\author{
Daniela BAIASU \\ https://doi.org/10.18662/lumproc/gekos2020/10
}

How to cite: Baiasu, D. (2020). Ethics and Open Sources. In A. Grigorescu \& V. Radu (vol. ed.), Lumen Proceedings: Vol. 11. 1st International Conference Global Ethics - Key of Sustainability (GEKoS) (pp. 86-95). Iasi, Romania: LUMEN Publishing House.

https://doi.org/10.18662/lumproc/gekos2020/10 


\title{
Ethics and Open Sources
}

\author{
Daniela BAIASU1
}

Abstract

Ethics is a system of moral principles and methods applicable to all activities. The two terms in our research, ethics and open sources, seem to contradict each other because the activity of using information obtained through open sources respects the norms of ethics as long as the information is real and legally obtained. The evolution of information and technology led to changes in the private and public fields, both at the organizational and decision-making level. Through this study, we want to show that violating the rules of ethics in the field of open source can be done easily, although it is an area where many countries are deficient in taking measures to stop irregularities. By applying optimal management of information obtained from open sources, areas such as economic, educational, or social can be improved in a relatively short time and can generate increases in the areas in which they are applied. The search for information in open sources, as a resource and engine for development, has become a visible priority of classical methods. The benefits of technology can lead, intentionally or unintentionally, to breaches of ethical standards in obtaining and using information from open sources. The misuse of open-source information can lead to intentional or involuntary misinformation, as well as violations of fundamental rights.

Keywords: ethics; open sources; information; Internet; fake news.

\footnotetext{
${ }^{1}$ Valahia University from Targoviste, Romania, daniela baiasu@yahoo.com

(C) The Authors, LUMEN Conference Center \& LUMEN Proceedings.

Selection and peer-review under responsibility of the Organizing Committee of the conference
} 


\section{Introduction}

The concept of ethics can be defined as "that which is right or wrong, good or bad, fair or unfair, responsible or irresponsible, obligatory or permissible, praiseworthy or reprehensible. It is associated with guilt, shame, indignation, resentment, empathy, compassion, and care. It is interested in both character and conduct. It addresses both to public policy and to personal issues [17]. Responsibility does not belong only to the individual, but also to the society in which he lives. Therefore, this "becomes a synthesis between ethics and pragmatic-utilitarian" [3]. Open sources have become, over time, an important tool used to supplement and enrich the knowledge obtained through classical methods. The evolution of open source information, as well as technology, has led to changes in the private and public fields [11], both at the organizational and decision-making level. Thus, information from open sources such as media, virtual communities, or social networks, circulates and is transmitted at an extremely fast pace with a constantly growing dynamic. A large amount of information favors skeptical, dissident, and critical opinions that do not conform to the premises of scientific knowledge [25].

The two terms in our paper, ethics and open source, seem to contradict each other because the activity of using information obtained through open sources can comply with ethical norms, as long as the information is real and legally obtained. To support this claim, we can consider the classification made by Robert D. Steele, OSINT (Open Source Intelligence) expert, who states that open sources are "all data in public circulation and that can be legally obtained by any person, upon request or by direct observation" [22]. Moreover, by applying optimal management of information obtained from open sources, various areas (from economic to social) can be improved in a relatively short time [1].

So far, ethics regarding the distribution process has been discussed only in terms of intellectual property, security, and the right to an opinion [20].

In the open-source environment, the principles of ethics are broke by misinformation, a phenomenon known as fake news. Misinformation can be intentionally or unintentionally. Thus, failure to comply with moral principles by distributing fake news may be based on political, economic, or social reasons, by manipulating public opinion. On the other hand, involuntary misinformation can occur due to a lack of information, and this cannot be considered fake news if "information error is reported" [18].

The fake news process is quite dynamic, is most often encountered in the media, the main provider of information. Fake news is "fabricated 
information that mimics new media content as a form but not as an organizational process or intent" [14]. False news can lead to distrust of real information.

People who accept fake news mostly get it from social media and have a "reduced willingness to think critically or check information" [18].

Representatives of Facebook decided in 2017, following the publication of misinformation news about Donald Trump during the 2016 campaign, to replace the term fake news with false news, considering that it communicates "more clearly the information that is created to be confused with the real news and is intentionally falsified" [15]. In the opinion of Cristina Lupu, a member of the Center of Independent Journalism, the two terms cannot be associated, because "when fake news is made intentionally, with the role of polarizing and manipulating, false news appear rather in following a documentation error of the journalist" [16]. A significant increase in misinformation is observed in the propaganda process, in which news is created by political entities to influence the electorate [24].

In the online environment, there are a large number of sites specializing in the distribution of fake news. There are two types of sites:

- stand-alone sites, such as beforeitsnews.com that posted unrealistic news about US President Donald Trump's 2016 campaign. Following the promotion of conspiracy theories related to the Malaysia Airline Flight 17 case, it was classified by the American daily Washington Post journalist, Caitlin Dewey, as an "unbalanced and impertinent news site" [5];

- sites that mimic other official websites or media outlets, such as CBSnews.com.co, owned by Paul Horner and which had the same URL, design, and logo as the CBS news agency. Another site was Bloomberg.ma which, in 2017, ad an identical design to the one of the American economic news site bloomberg.com. As an example, the site published the fake news that the social network Twitter was bought for 31 billion dollars. Posting this news increased the network's shares by $8 \%$ [4]. Such examples are frequently encountered, and the consequences of their use have led to the falsification of data, social actions, economic measures, influencing politics, public opinion, etc.

\section{State of the arts}

The main data provider in obtaining information from open sources is the traditional media (news agencies, publications, radio, and television stations). Other open sources are libraries, the Internet, new media (digital technologies that use the Internet to provide information and entertainment), gray literature (conference proceedings, stockholder reports 
of private companies and literature before publication), respectively unclassified information that has distribution or limited public access and over which other companies and organizations have no ownership.

A big amount of information we want to know is available through both education and interaction. Over time, education has reached a low level due to time pressure, overwork, and human failure [12]. Referring to our field of research, "lack of ethics and credibility in the academic community leads to etbical abuse" [21]. To be able to develop, we need change, flexibility and the power to adapt both the human factor, education, but also technology, as a support for concrete actions carried out by different users.

The information management obtained from open sources is an important link between ethics and OSINF (Open Source Information). The term open brought many discussions. Even if the information is available, open, that does not mean that those who benefit from it can process that data without complying with legal and ethical standards. Thus, open does not mean that certain restrictions do not exist, but only that some of the information can be obtained without costs, but with the distribution of data on the needs and preferences of those who access the information.

The most common discussions regarding the observance of ethical norms refer to OSINF in the new media (mainly social networks).

Posting personal data does not give the right to be used other than for what it was originally posted. To benefit from this data, the owner must give his consent. However, the data available in open sources may have been published by third parties and not by the owners. In these cases, noncompliance with ethical norms can lead to the violation of certain rights, such as the right to privacy, the right to intellectual property, copyright, etc. However, "online communities are characterized by ethical principles that, although they do not require explicit formalization, regulate the life of the community" [20].

Danah Boyd, a researcher at Microsoft, declared that "publishing and open access to certain content is not equivalent to requesting that it be distributed, aggregated, or modified in any way" [6].

\section{Research methodology}

The search for information in open sources has become a visible priority of classical methods. This action is also observed in the large number of studies conducted in this field. We used open-source documentation as a means, using the Internet and the resources provided by it. We analyzed the wearesocial.com and statista.com sites and based on the data obtained from these sources we extracted parameters that led to a 
statistical and comparative analysis regarding the use of the Internet in the period 2016-2019, on different devices and the purpose of its use. The limits of the research are represented by the use of existing data in the online environment.

Data posted by wearesocial.com revealed that the number of global internet users increased significantly from 3.77 billion users in 2016 (50.47\% of the global population) to 4.54 billion in 2019 (58.5\% of the global population). Thus, an increase of $8 \%$ of the total global population was registered in the period 2016-2019. In comparison, the data posted by statista.com also revealed a notable increase in the number of internet users. In 2016 there were 3.61 billion users, a number that reached 4.57 billion users, an increase of $9.36 \%$ compared to the number of population worldwide.

We also wanted to highlight the impact rate of fake news, analyzing the statistics produced by statista.com and europarl.europa.eu (European Parliament). Both studies had the same question (How often do you come across news that you think distorts reality or are they even false?), A close number of respondents (26567 and 26000 respectively) from the same countries (EU member states). The studies were conducted in the same period, in 2018 [19].

\section{Results}

Through our study, we will integrate information on the number of open source users by accessing the Internet and the rate of fake news among people who access the online environment.

Documentation from studies that highlighted the frequency of internet use provided results on 4 levels.

Wearesocial.com (global media agency) and Hootsuite (social media management platform, based in Canada) published, in January 2019, the report "Digital 2019: Global Internet accelerates" [26] which showed that, compared to 2016, the number of users of The Internet has grown considerably in 2019 [fig. 1]. 


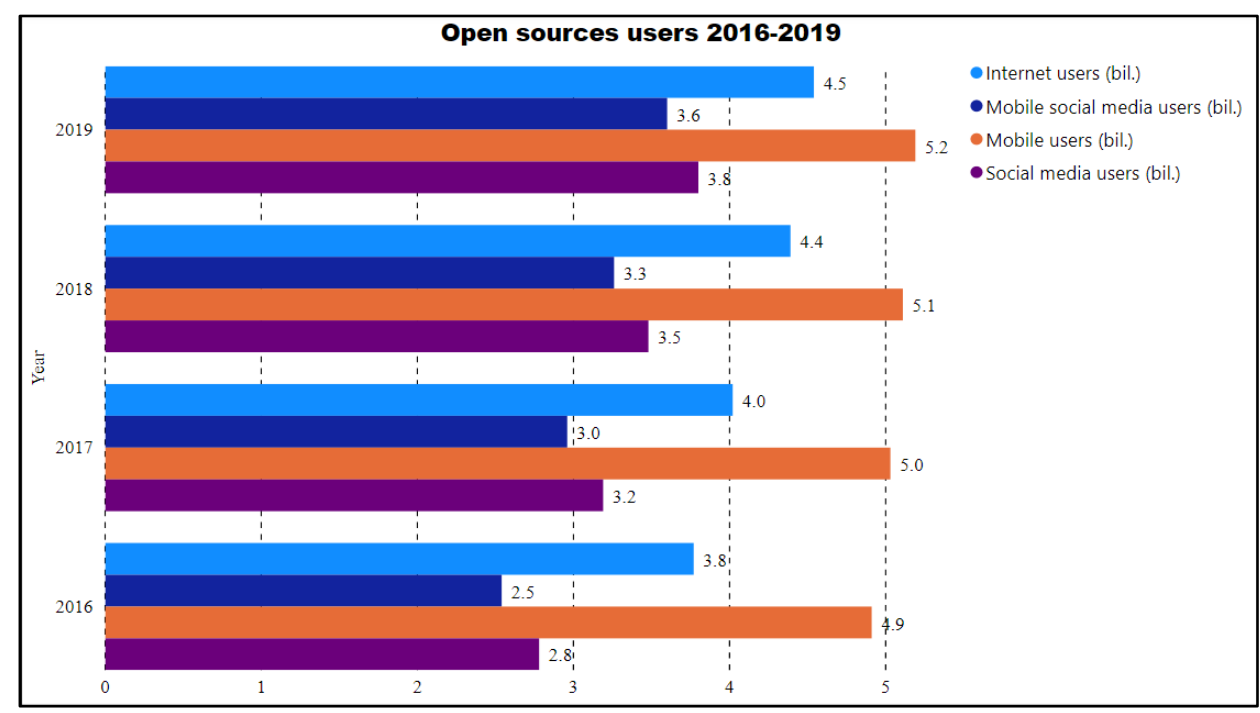

Fig. no. 1 Evolution of open sources users' number in the period 2018-2019

source: author processing

We can observe a systematic growth trend on the 4 types of accesses. Access to technology can be considered the main link between people and the online environment. To highlight a large number of online searches, the Google [10] search engine estimates that 88,787 GB of traffic is used in a second.

Increasing access to the Internet is giving an increasing number of users access to open-source information. But, as we mentioned, this free access does not guarantee that everything available is real and ethical.

This is also visible in the two studies analyzed to observe the impact rate of fake news on the population in the EU28.

The results of the two studies indicated that $37 \%$ of respondents observe daily or almost daily news that misinforms or does not correspond to reality, $31 \%$ observe at least once a week, $12 \%$ several times a month, and $17 \%$ rarely or never. $3 \%$ of respondents did not answer that they do not know how many times.

Respondents in Greece mostly observe such news daily or at least once a day (55\%), those in France and Ireland at least once a week (36\%), those in Cyprus several times a month (20\%)), those in Finland rarely or never $(29 \%)$, and those in Malta have the highest percentage in the category "do not know" (12\%). Regarding the respondents from Romania, 41\% stated that they observe fake news daily or almost every day, $27 \%$ at least 
once a week, 9\% several times a month, 16\% rarely or never, and 7\% do not know [fig. 2].

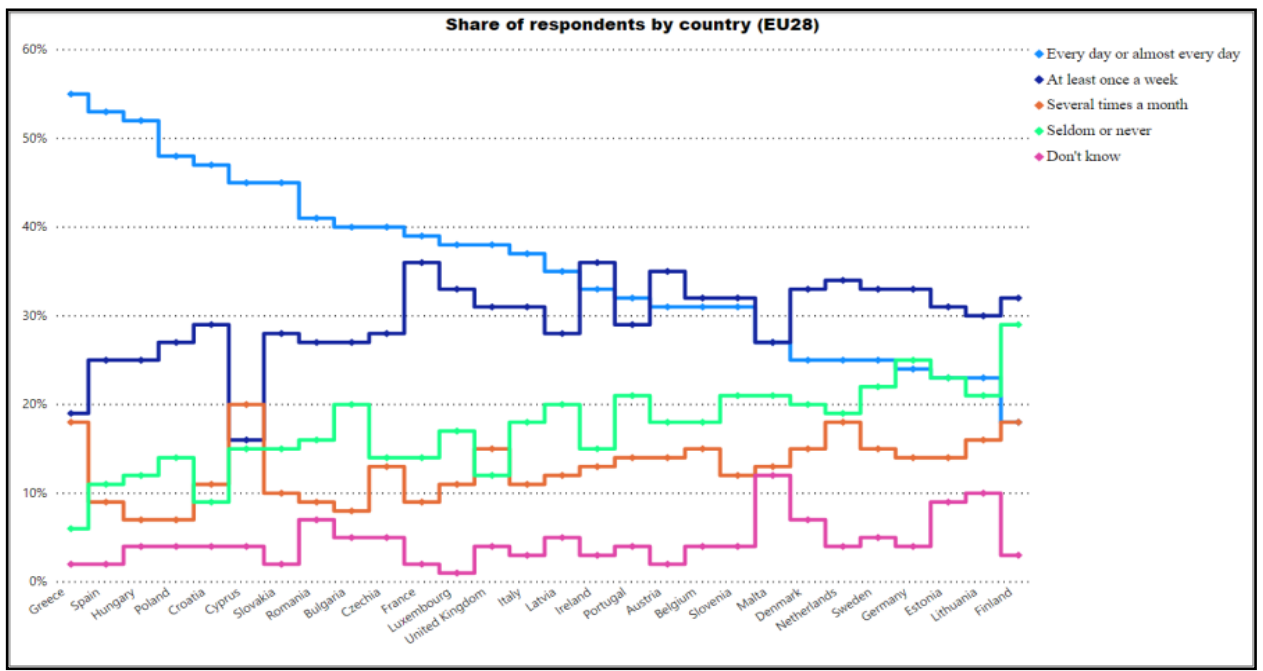

Fig. no. 2 Share of respondents in the EU countries about observing fake news source: author processing

The countries that most often notice the false news are countries mainly Eastern European or with a very close social culture such as Greece, Spain, Cyprus. Starting from the premise that open source users access mainly local sites and less international sites, we could believe that those countries are also the main generators of fake news. A deep analysis could be subject to further development, and analysis of the sites accessed in terms of national versus international and a more detailed analysis of the signals about fake news could offer information about their origin. At the same time a reason for a careless attitude about the veridicality of the content presented on open sources, and the ethics of providing, voluntarily or involuntarily, flowed content, may reside in the fact that after the 2000 s Eastern European countries began to introduce legislation for copyright.

To counter the posting of misinformation in the online environment, a group of experts has been set up in the European Union. The expert group proposed as measures: increasing the transparency of online sources, promoting media and information literacy, developing applications that prevent misinformation and adapting to developing technology, promoting ongoing research on the impact of misinformation in Europe to assess measures taken by various states and guaranteeing the diversity and sustainability of the news media ecosystem [13]. 


\section{Daniela BAIASU | Lumen Proceedings 11 | GEKoS2020}

Globally, the governments of some countries have imposed measures such as fines (United States, Russia, Brazil, and Ireland), investigation (Turkey, Kazakhstan, and UK), Internet shutdown (India), arrest (Bahrain, Bangladesh), online information (Belgium, Canada, and Denmark) or trial (Israel) [7]. The GMA News Online news agency announced [9] that the Union of Journalists of the Philippines together with the Center for Media Freedom and Responsibility created, in 2017, a plug-in for Google Chrome that helps identify fake news posted on the social networking site Facebook. Facebook, the network with the fakest news posts, is among those that react by removing pages, accounts, or groups that post fake news. In March 2017, they announced that they had deactivated several pages and accounts in Romania and the United Kingdom [8].

\section{Conclusions}

The result of the research revealed that accessing information from the online environment can lead to violations of ethical rules. The evolution of technology has forced the authorities to adapt their measures against the phenomenon of fake news, although many states are deficient, for the time being, in this field. In the opinion of Damian Tambini, an associate of the Institute for Public Policy Research, in most cases monitoring and verifying information would be sufficient as measures [23].

The benefits of technology can lead, intentionally or unintentionally, to breaches of ethical standards in obtaining and using information from open sources. Research in this area has shown that the number of internet users is constantly growing, and the beneficiaries of the information notice false news every day.

OSINF offers cultural, educational, social, and economic benefits. But, according to American philosopher John Rawls, "filtering some for the sake of message effectiveness is unethical" [2]. Disadvantages, such as misinformation, breach of several fundamental rights, can greatly affect ethical norms. Therefore, the responsibility for providing accurate data lies with both the provider and the user. As for the person who provides the information, it is important to know what the purpose is and the limits within which he is willing to provide. On the other hand, the one who uses the information has the moral duty to use only what is ethical and real.

When we talk about ethics and OSINF, we can say that the balance sheets can be influenced by interests, actions taken at the level of actors present in political, economic, and social life. To maintain a balance between 
the two, measures are needed to combat the fake news process or to tighten the existing ones in the case of some countries.

\section{References}

[1] Andregg MM. Intelligence Ethics. Center for the Study of Intelligence and Wisdom, 2007. $52 \mathrm{p}$.

[2] Bay M. The ethics of psychometrics in social media: A Rawlsian approach. Proceedings of the 51st Hawaii International Conference on System Sciences; 2018.

[3] Croitor E. Ethics of Responsibility? Some postmodern views. Procedia-Social and Behavioral Sciences, 2014;149, pp. 253-60.

[4] De la Merced MJ, Goldstein M. Twitter Shares Jump After Faked Bloomberg Report. The New York Times; 2015.

[5] Dewey C. A comprehensive guide to the web's many MH17 conspiracy theories. The Washington Post, 2014.

[6] Eijkman QAM, Weggemans D. Open Source Intelligence and Privacy. Dilemmas: Is it time to reassess state accountability?. Journal; 2013.9 p.

[7] Flamini D, Funke D. A guide to anti-misinformation actions around the world, 2019.

[8] Gleicher Nl. Removing Coordinated Inauthentic Behavior From the UK and Romania. facebook.com [Internet], 2017 [Accessed 16 March 2020]. Available from: https://about.fb.com/news/2019/03/removing-cib-uk-and-romania/

[9] GMA News Special Assignments Team. More 'fake news' sites blacklisted by NUJP, CMFR [Internet], 2019 [Accessed 16 March 2020]. Available from: https://www.gmanetwork.com/news/news/nation/635799/more-fake-newssites-blacklisted-by-nujp-cmfr/story/

[10] Google [Internet] Available from: https://www.internetlivestats.com/onesecond/\#google-band

[11] Grigorescu A, Lincaru C, Pîrciog S, Chițescu RI. Competitiveness and sustainable development in public services. Management \& Marketing. Challenges for the Know;edge, 2015, 14 (1): 108-129. doi: 10.2478/mmcks-2019-0008.

[12] Gruber G. Generalități despre etică, morală și deontologie. Un scurt istoric, 2015, pp. 2548

[13] High level Group. A multi-dimensional approach to disinformation. Luxembourg: Publications Office of the European Union, 2018. doi:10.2759/739290

[14] Lazer D, Baum MA, Benkler Y et al. The science of fake news. Science. 2018; 359 (6380): 1094-1096.

[15] Oremus W. Facebook Has Stopped Saying "Fake News". Slate; 2017.

[16] Petre A. Fake News sunt mai toxice ca niciodată pentru vïtorul tinerilor din România. Vice [Internet], 2018 [Accessed 16 March 2020]. Available from: https://www.vice.com/ro/article/mbywgv/fake-news-sunt-toxice-pentruromania 
[17] Pritchard MS, Goldfarb T. Ethics in the Sciece Classroom: An Instructional Giude for Secondary School Science Teachers. ENC Focus: A Magazine for Classroom Innovators, 2007; 8 (3).

[18] Rini R. Fake news and partisan epistemology. Kennedy Institute of Ethics Journal. 2017, 27(2), 43 p.

[19] Scientific Foresight Unit. Automated tackling of disinformation. European Parliamentary Research Service, 2019. doi: 10.2861/368879

[20] Stalder F, Sützl W, Capurro R, Britz J, Hausmanninger T, Nagenborg M et al. Ethics of sharing. Ethics. 2011;15(1): 9-21.

[21] Steele RD. E3i: Ethics, Ecology, Evolution, and Intelligence. Whole Earth Review; 1992, pp. 74-79.

[22] Steele RD. The Importance of Open Source Intelligence to the Military. International Journal of Intelligence and Counterintelligence 8, 1995, pp. 457-470.

[23] Tambini D. Fake news: public policy responses. Media Policy Brief 20, 2017

[24] Tandoc Jr. EC, Lim ZW, Ling R. Defining "fake news" A typology of scholarly definitions. Digital journalism, 2018; 6(2): 137-53.

[25] Waisbord S. Truth is what happens to news: On journalism, fake news, and post-truth. Journalism studies; 2018; 19(13): 1866-1878. doi: 10.1080/1461670X.2018.1492881

[26] We are Social Inc, DIGITAL 2019: GLOBAL INTERNET USE ACCELERATES [Internet], 2019 [Accessed 25 March 2020]. Available from: https://wearesocial.com/blog/2019/01/digital-2019-global-internet-useaccelerates 